
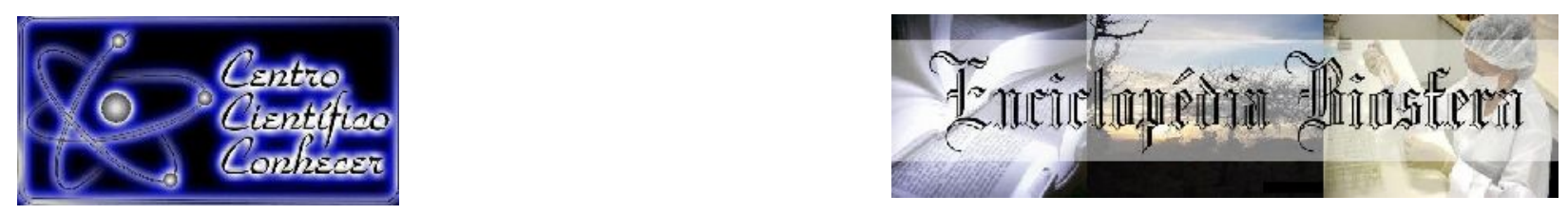

\title{
CARACTERIZAÇÃO TÉRMICA DE UM GALPÃO PARA CRIAÇÃO DE CAPRINOS NA ESTAÇÃO SECA EM SINOP - MT
}

\author{
Charles Campoe Martim ', Luana Bouvié2, Emília Garcez da Luz', Jamson \\ Justi $^{2}$, Marta Cristina de Jesus Albuquerque Nogueira ${ }^{3}$ \\ ${ }^{1}$ Mestrando em Física Ambiental, Universidade Federal de Mato Grosso, \\ Campus de Cuiabá-MT, Brasil (charleschp2011@hotmail.com) \\ 2Doutorando em Física Ambiental, Universidade Federal de Mato Grosso, \\ Campus de Cuiabá-MT, Brasil \\ 3 Professora Efetiva, Departamento de Arquitetura e Urbanismo, \\ Universidade Federal de Mato Grosso, Campus de Cuiabá-MT, Brasil
}

Recebido em: 22/09/2018 - Aprovado em: 23/11/2018 - Publicado em: 03/12/2018 DOI: 10.18677/EnciBio_2018B23

\begin{abstract}
RESUMO
Sabe-se que são vários são os fatores que influenciam o desempenho animal, e dentre estes estão, o genético, alimentar e ambiental. Pensando nisso, objetivou-se por meio deste trabalho verificar a condição térmica, por meio do cálculo de índices térmicos, oferecidos por um galpão destinado à criação de caprinos, construído em Sinop - MT e, com base nesta verificação, buscar soluções para garantir conforto térmico a esta categoria animal. Os dados foram coletados no período de 17/04 a 23/04 de abril de 2017, na unidade de produção animal da Universidade Federal de Mato Grosso - Campus de Sinop. O galpão analisado possui uma largura de quatro metros, comprimento de 32 metros e pé-direito de quatro metros e meio de altura, tendo sido construído com orientação no sentido leste-oeste. Os índices analisados mostraram que tanto no interior do galpão, quanto fora, em todos os dias avaliados, os caprinos se encontrariam, nos diferentes horários, submetidos a algum tipo de estresse térmico, que poderia ser minimizado utilizando-se de intervenções ambientais primárias como sombreamento, aspersão de água sobre o telhado nas horas mais quentes do dia, e principalmente a retirada do canavial, situado na orientação sul da instalação, a fim de melhorar a ventilação natural.
\end{abstract}

PALAVRAS-CHAVE: Caprinocultura, condições ambientais, índices térmicos.

\section{THERMAL CHARACTERIZATION OF A SHED FOR THE CREATION OF GOATS IN THE DRY SEASON IN SINOP - MT}

\begin{abstract}
It is known that several factors influence animal performance, including genetic, food and environmental factors. With this in mind, the objective of this work was to verify the thermal condition, by calculating thermal indices, offered by a shed for goat farming, built in Sinop - MT and, based on this verification, seek solutions to ensure comfort thermal a is this animal category. The data were collected from April 17 to April 23, 2017, at the animal production unit of the Federal University of Mato Grosso - Sinop Campus. The shed analyzed has a width of four meters, length of thirty-two meters and foot height of four and a half meters high, having been constructed with east-west orientation. The indices analyzed showed that both inside and outside the
\end{abstract}


shed, on all evaluated days, the goats would be at different times subjected to some type of thermal stress, which could be minimized using primary environmental interventions such as shading, sprinkling of water on the roof in the hottest hours of the day, and especially the removal of the cane field, located in the southern orientation of the facility in order to improve natural ventilation.

KEYWORDS: Environmental conditions, goat breeding, thermal indexes.

\section{INTRODUÇÃO}

O ambiente influencia diretamente no comportamento fisiológico dos animais, sendo a temperatura um dos principais fatores de estresse. Os animais necessitam de intervalos específicos para o conforto térmico, que compreendem a zona de conforto térmico (ZCT) na qual o intervalo de temperatura identifica onde o animal tem um gasto mínimo para manter a temperatura corporal, não passando por frio nem por calor (BAÊTA; SOUZA, 2010). Dessa forma, nos horários de maior temperatura do dia, os animais tendem a aumentar a frequência respiratória e diminuir a ingestão de alimentos a fim de manter a temperatura corporal constante, diminuindo assim o ganho de peso, consequentemente comprometendo 0 desempenho, pois parte da energia adquirida pelos alimentos está sendo utilizada na perda de calor corporal (SOUZA et al., 2005, PEREIRA et al., 2011).

Os índices térmicos ambientais como ITGU (Índice de temperatura de Globo Negro e Umidade) e $I T U$ (Índice de temperatura e Umidade) têm sido amplamente utilizados em estudos de conforto ambiental. Isto se deve ao fato de caracterizarem de forma mais apropriada a condição térmica do ambiente, uma vez que estes incluem os efeitos de temperatura, umidade relativa, radiação e velocidade do ar (SANTOS et al., 2014).

A influência do ambiente térmico sobre os animais de produção varia com a espécie, raça, idade, peso e sexo. Pensando nisso, várias raças exóticas de caprinos vêm sendo inseridas, principalmente no nordeste brasileiro, região cujo clima é considerado estressante até para animais adaptados ao calor, com o objetivo de aumentar a produção tanto de carne como de leite (CEZAR et al., 2004; SANTOS et al., 2005; RIBEIRO et al., 2008). Sendo assim, as instalações destinadas ao alojamento animal devem ser dimensionadas a fim de diminuir o efeito do clima, tal como chuva, radiação solar, vento, temperatura e umidade, e garantir o máximo desempenho genético do animal (BAÊTA; SOUZA, 2010; LEITE et al., 2012).

Com base na necessidade de entender a interação das raças de caprinos com o ambiente, e se as instalações realmente estão garantindo o conforto necessário para a máxima produção, vários trabalhos vêm sendo desenvolvidos, principalmente no nordeste brasileiro, que apresenta altas temperaturas e baixa umidade durante todo o ano. Santos et al. (2014) trabalharam com duas raças de caprinos em Teresina-PI, a fim de avaliar o conforto animal nas instalações; os animais da raça Marota apresentaram frequência respiratória menor quando comparado aos da raça Saanen, que não são adaptadas a região. Já Souza et al. (2005), trabalhando com diferentes raças como, 1/2 Boer + 1/2 SRD, 1/2 Anglo-Nubiana + 1/2 SRD, $1 / 2$ Savana + 1/2 SRD, $1 / 2$ Kalarari + 1/2 SRD e $1 / 2$ Moxotó + 1/2 SRD, no conforto térmico de um aprisco, encontraram que todos os grupos estudados mantiveram a homeotermia, pois são adaptadas às condições ambientais do nordeste brasileiro.

Em Mato Grosso, observa-se a inexistência de trabalhos relativos ao ambiente térmico de criação de caprinos, apesar da relevância do assunto, visto que 
as criações têm aumentado. Assim, objetivou-se verificar a condição térmica oferecida por um galpão destinado à criação de caprinos, construído em Sinop - MT, e com base nesta verificação, buscar soluções para garantir conforto térmico a esta categoria animal.

\section{MATERIAL E MÉTODOS}

O trabalho foi desenvolvido no galpão da unidade de produção animal da Universidade Federal de Mato Grosso, campus de Sinop-MT, no período de 17 de abril a 23 de abril, no ano de 2017, com intervalos de duas horas entre leituras, sendo estas realizadas nos seguintes horários: 7, 9, 11, 13, 15 e 17 horas. A região é classificada segundo Köppen como Aw (tropical quente e úmido) com duas estações bem definidas, chuvosa (outubro a abril) e seca (maio a setembro), com temperatura média anual de $24,70^{\circ} \mathrm{C}$ e precipitação de $1.974,47 \mathrm{~mm}$ (SOUZA et al., 2013).

O galpão possui 20,5 metros de comprimento e 7,5 metros de largura com pédireito de 4,35 metros e está orientado no sentido leste-oeste. Foi construído inteiramente de madeira e é aberto em todas as laterais, possuindo somente as muretas de balaústra ripadas para a divisória das acomodações dos animais, as telhas do galpão são de fibrocimento com quatro anos de uso e o piso é de chão batido. O Quadro 1 apresenta as propriedades térmicas dos materiais componentes do galpão estudado.

QUADRO 1 - Densidade de massa aparente ( $r$ ), condutividade térmica (I) e calor específico (c) de materiais do galpão avaliado em Sinop-MT.

\begin{tabular}{|c|c|c|c|}
\hline Material & $\rho\left(\mathrm{kg} \cdot \mathrm{m}^{-3}\right)$ & $\lambda\left(\mathrm{W} . \mathrm{m} \cdot \mathrm{K}^{-1}\right.$ & $\mathrm{c}\left(\mathrm{kJ} . \mathrm{Kg} \cdot \mathrm{K}^{-1}\right)$ \\
\hline $\begin{array}{c}\text { Madeira com densidade de } \\
\text { massa aparente elevada }\end{array}$ & $800-1000$ & 0,29 & 1,31 \\
\hline Telha de fibro-cimento & $1400-1800$ & 0,65 & 0,84 \\
\hline
\end{tabular}

FONTE: ABNT NBR 15220:2 (2005)

Foram realizadas medições de temperatura do ar $\left(T_{a r}\right)$, temperatura de ponto de orvalho $\left(T_{p o}\right)$, e temperatura de globo negro $\left(T_{g n}\right)$ no interior e fora da instalação. Além de temperatura da telha e solo no interior do galpão. Com esses dados foram calculados o ITGU e a carga térmica de radiação (CTR) nos diferentes horários e dias de avaliação.

$\mathrm{Na}$ face sul do galpão de caprinos, há uma área com plantação de cana a quatro metros da lateral. $\mathrm{Na}$ face norte, o beiral está posicionado a três metros de altura e com prolongamento de dois metros e meio, construído para evitar a incidência da radiação solar direta no interior do galpão, enquanto os beirais remanescentes possuem dimensão de meio metro. As medições foram realizadas no interior do galpão em quatro pontos diferentes, conforme a Figura 1, sendo dois na face sul ( $A$ e $B$ ) e os outros dois na face norte ( $C$ e $D)$, com os quais foi obtida uma média representativa do galpão, visto que os pontos apresentaram valores semelhantes, além de um ponto externo ao galpão. 

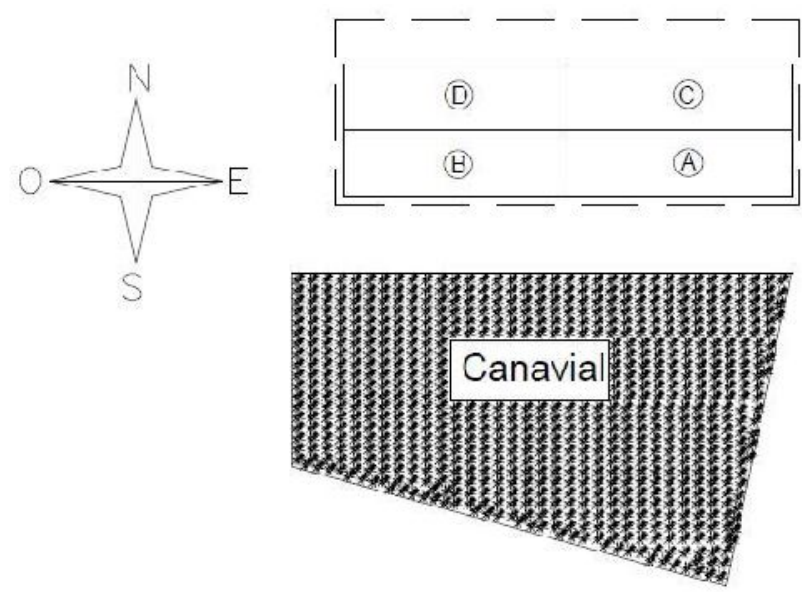

FIGURA 1 - Esquema de distribuição dos pontos de coleta no galpão avaliado em Sinop-MT.

Fonte: Os autores (2018)

Para mensurar $T_{a r}$ e $T_{p o}$ foi instalado um termo-higrômetro com data logger, a meio metro a partir do nível do solo, programado para registrar os dados a cada duas horas. Para $T_{g n}$ utilizou-se o termômetro de globo digital tipo espeto TGD - 300 da Intrutherm, para a medição da temperatura da telha e solo utilizou-se o termômetro infravermelho MT-350 da Minipa. Para a velocidade do vento utilizou-se um termo-higrômetro-anemômetro-luxímetro sempre posicionado na altura de referência dos animais, com sentido norte-sul.

A $T_{\text {po }}$ foi estimada através da equação de Tetens (Equação 1) adaptada em Mehdizadeh et al. (2017), já para o cálculo do ITGU utilizou-se a metodologia proposta por Buffington et al. (1981) (Equação 2), enquanto para CTR seguiu-se a metodologia citada por Esmay (1969) (Equação 3) e para a temperatura radiante média (TRM) descrita em Furtado et al. (2008) (Equação 4), sendo que:

onde

$$
T p o=\frac{237,3 \log \left(\frac{e}{0,6407 \%}\right)}{7,5-\log \left(\frac{\varepsilon}{0,81078}\right)}
$$

$T_{p o}$ : temperatura do ponto de orvalho $\left({ }^{\circ} \mathrm{C}\right)$

e: pressão parcial de vapor (Kpa)

$$
I T G U=T_{g n}+0,36 T_{p o}+41,5
$$

onde

$T_{p o}$ : temperatura de ponto de orvalho $\left({ }^{\circ} \mathrm{C}\right)$;

$T_{g n}$ : temperatura de globo negro $\left({ }^{\circ} \mathrm{C}\right)$.

$$
C T R=\sigma(T R M)^{4}
$$

onde

CTR: carga térmica de radiação $\left(\mathrm{W} . \mathrm{m}^{-2}\right)$

б: constante de Stefan-Boltzman $\left(5,6710^{-8} \mathrm{~W} \cdot \mathrm{m}^{-2} \cdot \mathrm{k}^{-4}\right)$

Já a TRM, expresso em $K$, é obtida através da seguinte equação:

$$
T R M=100 \cdot\left[2,51, v^{\frac{1}{3}},\left(T_{g n}-T_{a r}\right)+\left(\frac{T_{g m}}{100}\right)^{4}\right]^{\frac{1}{4}}
$$


onde

v: velocidade do ar $\left(\mathrm{m} . \mathrm{s}^{-1}\right)$.

Para avaliar se o ambiente estaria proporcionando conforto térmico ficou definido que um valor de ITGU de 74 seria a referência para o limite de conforto (PEREIRA et al., 2011; NATIONAL WEATHER SERVICE, 2017). A análise do ambiente térmico foi feita de forma descritiva, utilizando-se de gráficos de linha das médias dos valores observados para cada dia mensurado, em função dos horários de coleta dos dados. Além da utilização de medidas de posição e dispersão, como média e desvio-padrão.

\section{RESULTADOS E DISCUSSÃO}

\section{Índice de temperatura de globo negro e umidade (ITGU)}

Com base na literatura observou-se que os animais quando expostos a um ITGU de até 74 estão em condição de conforto, para valores de 74 a 78 em condição de alerta, entre 79 a 84 em condição perigosa, e valores superiores a 84 em condição de emergência (NATIONAL WEATHER SERVICE, 2017). Segundo Pereira et al. (2011), o ITGU de conforto para caprinos fica abaixo de 74, sendo valores superiores considerados de estresse térmico.

A Figura 2 mostra a variação do ITGU em função dos horários de coleta dos dados para cada dia analisado, para o exterior e o interior do galpão. Foi acrescentado ao gráfico uma linha de referência contínua no valor de 74 (cor laranja).
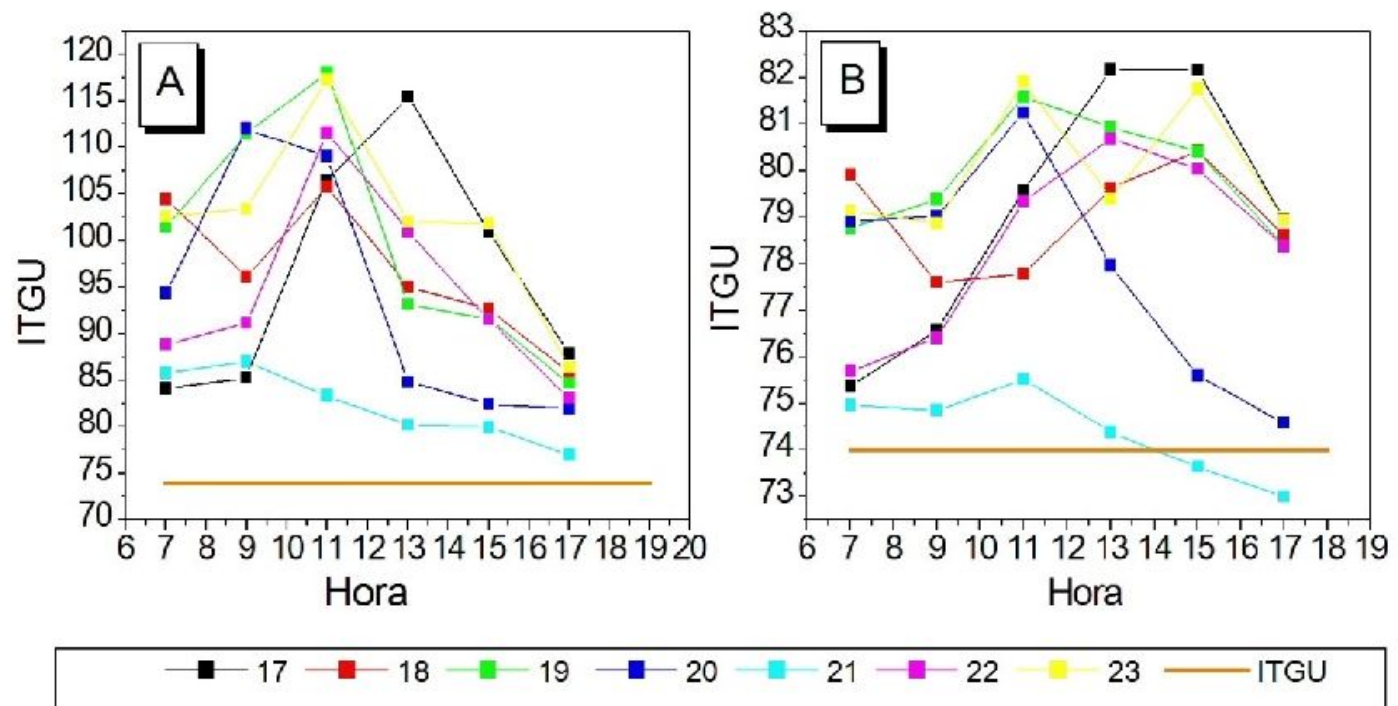

FIGURA 2 - Variação do índice de temperatura e globo negro e umidade (ITGU) ao longo das 7, 9, 11, 13, 15 e 17 horas nos dias 17, 18, 19, 20, 21, 22 e 23 de abril de 2017 externo ao galpão (A) e no interior do galpão (B) em Sinop-MT.

FONTE: Autores (2018)

Para todos os dias, o ITGU externo (Figura 2A) apresentou variação ao longo do dia, saindo de valores próximos a 85 e 105 no primeiro horário do dia, variando de 85 até 115 às 11 horas da manhã, e decrescendo em seguida. No dia 21 observou-se uma frente fria sobre a região que contribuiu para que o ITGU apresentasse um comportamento decrescente, de 85 às 7 horas para 77 às 17 horas, configurando um dia atípico. O ITGU externo ficou acima do considerado 
confortável para todos os dias, e, segundo a classificação da National Weather Service, a situação dos animais submetidos a esse tipo de ambiente estaria em condição de emergência.

Nas primeiras leituras no interior do galpão (Figura 2B), às 7 horas, o ITGU variou de 75 a 90 , apresentando comportamento crescente, chegando a 91 às 11 horas, horário mais crítico do dia, e posteriormente decresceu até 78 , às 17 horas, para a maioria dos dias avaliados. No dia 21 a frente fria também influenciou o ITGU no interior do galpão, que foi decrescendo ao longo do dia, saindo de 75 até 72 às 17 horas. No interior do galpão, somente no dia 21 às 15 horas os animais estariam em conforto, enquanto nos outros dias, principalmente às 13 horas, os animais estariam sob estresse térmico e em condições perigosas.

No dia 17, um dos dias mais críticos analisados neste experimento, o galpão proporcionou uma redução de $28,97 \%$ no ITGU às 13 horas, com 115,45 externo e 82 interno, que, apesar de ser uma redução significativa, não garantiria o conforto térmico. No dia 21, que foi atípico devido a frente fria, o ITGU externo e interno foram de 87 e 74,86 às 9 horas, com uma redução de apenas 13,95\%.

Em estudo de conforto térmico no interior de galpão, com ovinos nativos, Ribeiro et al. (2008) encontraram o ITGU variando de 75,1 a 82,1 as 7 e 15 horas, e caprinos, Leite et al. (2012) encontraram ITGU de 69,8 a 82,9 as 3 e 15 horas, que foram semelhantes aos resultados encontrados neste estudo (Figura 2 B).

\section{Carga térmica radiante (CTR)}

Na Figura 3 é apresentada a variação da CTR em função dos horários de coleta dos dados para cada dia analisado, tanto para o exterior e o interior do galpão.

Na Figura 3 (A) observa-se que a CTR externa variou ao longo do dia, sendo que os menores valores registrados ficaram próximos aos $450 \mathrm{~W} \cdot \mathrm{m}^{-2}$ e os maiores registrados entre $11 \mathrm{~h}$ e $13 \mathrm{~h}$ ficaram próximos aos $750 \mathrm{~W} . \mathrm{m}^{-2}$. Verificou-se que ocorreu um pico em torno de 11 horas, isto foi devido ao fato do ar externo não reter o calor, principalmente no período da seca, e a umidade do ar é baixa.
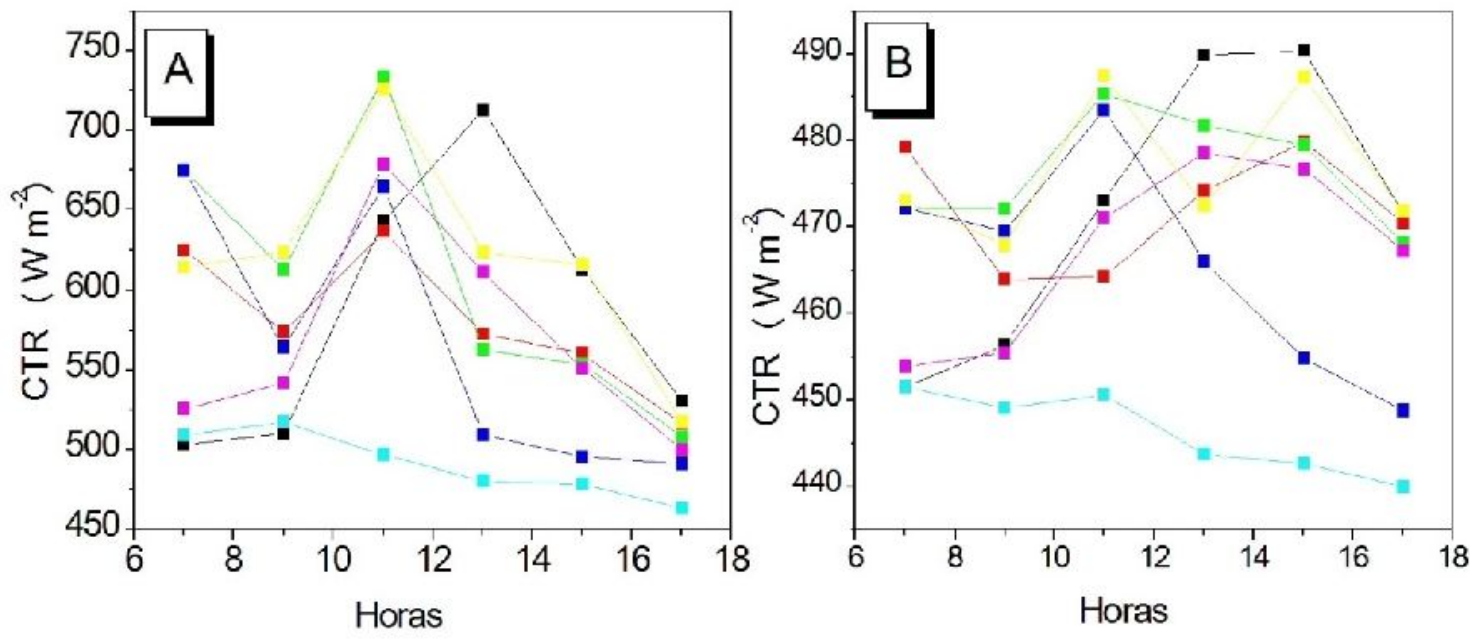

$-17-18-19-20-21-22$

FIGURA 3 - Variação da carga térmica radiante (CTR) ao longo das $7,9,11,13,15$ e 17 horas nos dias 17, 18, 19, 20, 21, 22 e 23 de abril de 2017 fora do galpão (A) e no interior do galpão (B) em Sinop-MT.

FONTE: Autores (2018) 
Para CTR no interior do galpão, Figura 3 (B), em praticamente todos os dias os maiores valores se situaram entre às 13 e 15 horas, em função da estrutura, durante o período da manhã, tender a absorver a radiação, principalmente pelo telhado, que com o tempo fica escuro, liberando na parte da tarde no interior do galpão o calor na forma sensível. Observa-se que, para o interior do galpão, os valores de CTR variam menos, entre aproximadamente 440 e $490 \mathrm{~W} \cdot \mathrm{m}^{-2}$. No dia 17 a CTR foi a mais crítica, com valores externo e interno de 712 e $489 \mathrm{~W} \cdot \mathrm{m}^{-2}$ às 13 horas, indicando uma redução no interior do galpão de $31,32 \%$.

Souza et al. (2005), ao analisarem o ITGU no interior de um galpão para caprinos, encontraram valores de 79,15 no período vespertino e de 71,25 no matutino, com uma diferença de 7,9 entre os períodos, pois a estrutura tende a absorver calor na parte da manhã e liberá-lo na parte da tarde. Santos et al. (2005), trabalhando com raças exóticas e naturalizadas no nordeste brasileiro, encontraram que a temperatura retal e a frequência respiratória são diferentes estatisticamente ao longo do dia, sendo maiores no período da tarde quando comparado aos da manhã.

Em estudo de conforto térmico no interior de galpão, com ovinos nativos, Ribeiro et al. (2008) encontraram CTR variando de 483,8 a $543,6 \mathrm{~W} \mathrm{~m}^{-2}$ as 7 e 15 horas e para caprinos, Leite et al. (2012) encontraram CTR variando de 464,9 a $547,2 \mathrm{~W} \mathrm{~m}^{-2}$ as 3 e 15 horas, que foram semelhante aos resultados obtidos neste estudo (Figura $3 \mathrm{~B}$ ).

\section{Elementos climáticos do galpão em Sinop-MT}

$\mathrm{Na}$ Tabela 1 são apresentados os valores máximos, mínimos, médios e o desvio-padrão $(\alpha)$ estimados para as variáveis temperatura da telha, do ar externo e interno ao galpão e do solo; umidade relativa; velocidade do ar; ITGU e CTR internos e externos.

TABELA 1 - Temperatura, umidade relativa, velocidade do ar, ITGU e CTR em condição interna e externa de um galpão para caprinos em Sinop-MT.

\begin{tabular}{ccccc}
\hline Variáveis & Máx. & Mín. & Média & $\sigma$ \\
\hline T. Telha $\left({ }^{\circ} \mathrm{C}\right)$ & 62,0 & 21,1 & 33,8 & 9,8 \\
T. Ar Ext. $\left({ }^{\circ} \mathrm{C}\right)$ & 42,3 & 23,2 & 32,2 & 5,2 \\
T. Ar Int. $\left({ }^{\circ} \mathrm{C}\right)$ & 34,1 & 22,3 & 27,8 & 2,9 \\
T. solo $\left({ }^{\circ} \mathrm{C}\right)$ & 34,3 & 22,7 & 28,1 & 2,7 \\
U.R. $(\%)$ & 95,4 & 57,2 & 78,8 & 9,5 \\
V. Ar $\left(\mathrm{m} . \mathrm{s}^{-1}\right)$ & 2,0 & 0,0 & 0,1 & 0,2 \\
ITGU int. & 82,2 & 72,8 & 78,4 & 2,4 \\
ITGU ext. & 118,6 & 77,0 & 95,3 & 11,4 \\
CTR int. $\left(\mathrm{W} . \mathrm{m}^{-2}\right)$ & 490,7 & 439,4 & 468,0 & 13,4 \\
CRT ext. $\left(\mathrm{W} \cdot \mathrm{m}^{-2}\right)$ & 733,6 & 463,2 & 574,4 & 73,2 \\
\hline
\end{tabular}

temperatura do ar máxima, média e mínima (Máx., Méd. e Mín.), desvio padrão ( $\sigma$ ), temperatura da telha (T. Telha), temperatura do ar externo (T. Ar Ext.), tempereatura do ar interno ( $\mathrm{T}$. Ar Int.), temperatura do solo interno (T. solo), umidade relativa interna (U.R.), velocidade do ar interno (V. Ar.), índice de temperatura de globo negro e umidade interno e externo (ITGU int. e ITGU ext.), carga térmica radiante (CTR int. e CTR ext.). FONTE: Autores (2018) 
A telha utilizada no experimento foi instalada há quatro anos, o que gera um escurecimento devido ao acúmulo de partículas e detritos, tornando assim o telhado uma superfície com maior absorção de radiação, com consequente transmissão para o interior da instalação. A temperatura da telha chegou a máxima de $62^{\circ} \mathrm{C}$ e minima de $21,1^{\circ} \mathrm{C}$, indicando significativa oscilação durante o dia, com média de $33,8 \pm 9,8^{\circ} \mathrm{C}$, enquanto a temperatura do ar interna foi de $27,8^{\circ} \mathrm{C} \pm 2,9^{\circ} \mathrm{C}$ e a externa de $32,2^{\circ} \mathrm{C} \pm 5,2^{\circ} \mathrm{C}$.

Furtado et al. (2003) trabalharam com a interferência dos diferentes tipos de telhas no conforto térmico de frangos, e encontraram que, nas horas com as temperaturas mais elevadas, o galpão apresentou condições acima da ideal para frangos de corte e concluíram que a tipologia da telha tem uma forte influência nas condições internas do galpão, das quais a telha de barro com nebulização e ventilação forçada apresentou um melhor desempenho. No mesmo trabalho, encontraram, para telha de fibrocimento, sem ventilação artificial, respectivamente, valores máximos e mínimos de temperatura de 30,87 e $26,13^{\circ} \mathrm{C}$, umidade relativa do ar de 71,94 e 52,10\%, ITGU de 81,16 e 76,57, e CTR de 509,46 e 479,66 W.m².

Observou-se que os resultados encontrados para temperatura do ar no interior do galpão, $27,8^{\circ} \mathrm{C} \pm 2,9^{\circ} \mathrm{C}$, estão muito próximos aos valores sugeridos por Baêta e Souza (1997) como referência para a zona de conforto térmico (ZCT) de caprinos, entre 20 e $30^{\circ} \mathrm{C}$, sendo que as temperaturas críticas inferior e superior (TCl e TCS) seriam de -20 e $34^{\circ} \mathrm{C}$, respectivamente.

Santos et al. (2005) em Patos-BA encontraram que em média, a temperatura das 9 e 15 horas de 21 de agosto a 06 de setembro do ano de 2002, no interior da instalação, foi de $31,3{ }^{\circ} \mathrm{C}$, acima da temperatura de conforto determinada para caprinos. Quando observado o efeito do horário sobre a temperatura, as temperaturas máxima, mínima, de globo negro e de bulbo seco foram maiores na parte da tarde.

O solo apresentou uma temperatura de $28,1^{\circ} \mathrm{C} \pm 2,7^{\circ} \mathrm{C}$, com tendência de comportamento análogo ao da temperatura do ar no interior do galpão, tanto para a máxima quanto para a mínima. A umidade relativa chegou a 95,4\%, $\pm 9,49 \%$ e velocidade do vento a $2 \mathrm{~m} \cdot \mathrm{s}^{-1}, \pm 0,25 \mathrm{~m} \cdot \mathrm{s}^{-1}$, apresentando um aumento perto do anoitecer e tendendo a sua máxima. No experimento, o valor chegou a $95,4 \%$ e decresceu até $57,2 \%$ no momento em que o ar foi aquecido, em torno das 13 horas. A umidade relativa para o conforto térmico de caprinos deve estar na faixa de 50 a 80\% (BAÊTA; SOUZA, 2010).

Santos et al. (2014), ao analisarem a temperatura do ar e umidade relativa durante o dia, perceberam que nos horários ocorria diferença significativa, com valor de $p<0,05$, tanto no período seco como chuvoso, e que o crescimento da $T_{g n}$ foi significativo e crescente até as 15 horas e constante até as 17-18 horas. Para caprinos, a parte vespertina do dia é mais estressante quando comparado a matutina no quesito conforto térmico (SANTOS et al., 2005; SANTOS et al., 2014).

Analisando os parâmetros fisiológicos de ovinos em instalações rurais na Paraíba, Cezar et al. (2004) encontraram a temperatura média, máxima e mínima no dia de 28,2, 33,2 e $23,3{ }^{\circ} \mathrm{C}$, respectivamente, umidade relativa de $54 \%$ e ITGU de 79, com valores mais críticos na parte vespertina do dia. Pereira et al. (2011) encontraram na sombra e no sol valores médios de ITGU de 86,4 e 92,4, respectivamente, ao estudaram o comportamento fisiológico de caprinos no município de Mossoró-RN.

Com relação aos índices, o ITGU externo e interno chegaram, respectivamente, a 118,57 $\pm 11,39$ e $82,22 \pm 2,45$. Os dados indicam que o ITGU 
interno ficou entre condição de conforto $(72,86)$ e perigosa $(82,22)$. Em contrapartida, o externo ficou em condição de alerta (77) e emergência $(118,57)$, com maior desvio padrão na medição externa.

A CTR seguiu a mesma tendência do ITGU, com valores externos e internos máximos de $733,61 \mathrm{~W} \cdot \mathrm{m}^{-2}$ e $490,66 \mathrm{~W} \cdot \mathrm{m}^{-2}$, e mínimos de $463,23 \mathrm{~W} \cdot \mathrm{m}^{-2}$ e 439,39 W. $\mathrm{m}^{-2}$, respectivamente. A CTR interna máxima foi cerca de $33 \%$ menor do que a externa, demonstrando que a cobertura reduziu a carga térmica. Conforme Baêta e Souza (2010), qualquer cobertura deve reduzir no mínimo em 30\% a CTR.

No que se refere à velocidade do vento, a máxima foi de $2 \mathrm{~m} . \mathrm{s}^{-1}$ e a média de $0,1 \mathrm{~m} \cdot \mathrm{s}^{-1}$. Segundo Mcdowell (1989), ventos que situam entre 1,3 a $1,9 \mathrm{~m} \cdot \mathrm{s}^{-1}$ são ideais para o conforto dos animais, à medida que velocidades próximas a $8 \mathrm{~m} \cdot \mathrm{s}^{-1}$ não são recomendadas. Acredita-se que a velocidade do ar tenha sido comprometida em função da presença do canavial situado próximo à face norte do galpão.

Os resultados encontrados demonstram a necessidade de se buscar alternativas para melhorar a condição interna do galpão e diminuir a CTR, podendo dessa forma ser sugerido, com base nas recomendações de modificações ambientais primárias de Baêta e Souza (2010), a pulverização de água sobre o telhado nas horas mais quentes do dia e o plantio de árvores na face norte do galpão, desde que estas apresentem a copa a no mínimo a altura da construção para sombrear o telhado. Com estas medidas acredita-se que estariam garantidos a ventilação natural e o aumento da umidade na instalação.

\section{CONCLUSÕES}

O galpão avaliado não foi capaz de oferecer um ambiente térmico adequado à criação de caprinos, uma vez que o ITGU mensurado no interior da instalação esteve acima do recomendado na literatura.

A implementação de algumas modificações ambientais básicas como proporcionar ventilação natural (respeitando-se uma distância mínima do canavial ao galpão), sombreamento por árvores ao redor do galpão e nos piquetes podem promover melhoria no ambiente de criação.

Além disso, a limpeza e posteriormente pintura externa do telhado de cor branca, aliado à aspersão de água sobre as telhas nos períodos mais quentes do dia, promoveria reduções de CTR e temperatura, visto que a telha teve uma forte influência sobre as condições interna do galpão.

\section{AGRADECIMENTOS}

Os autores agradecem a Coordenação de Aperfeiçoamento de Pessoal de Nível Superior (CAPES) e ao Conselho Nacional de Desenvolvimento Científico e Tecnológico (CNPq) pela concessão das bolsas de mestrado e doutorado aos autores para o desenvolvimento do trabalho, e ao Programa de Pós-Graduação em Física Ambiental (PPGFA) da Universidade Federal de Mato Grosso pelo incentivo à pesquisa.

\section{REFERÊNCIAS}

ABNT - Associação Brasileira de Normas técnicas . NBR 15220-2: Desempenho térmico de edificações - Parte 2: Métodos de cálculo da transmitância térmica, da capacidade térmica, do atraso térmico e do fator solar de elementos e componentes de edificações. Rio de Janeiro, 2005. 
BAÊTA, F. C.; SOUZA, C. F. Ambiência em edificações rurais, conforto animal. Viçosa, MG: 2 ed. UFV, 2010. 246 p.

BUFFINGTON, C. S.; COLLAZO-AROCHO, A; CANTON, G. H.; PITT, D. Black globe humidity comfort index for dairy cows. St. Joseph: ASAE, 1977. 19 p. Disponível em: <http://dx.doi.org/10.13031/2013.34325> . Doi: 10.13031/2013.34325

CEZAR, M. F.; SOUZA, B. B.; SOUZA, W. H.; FILHO, E. C. P.; TAVARES, G. P.; MEDEIROS, G. X. Avaliação de parâmetros fisiológicos de ovinos Dorper, Santa Inês e seus mestiços perante condições climáticas do trópico semi-árido nordestino. Ciência e Agrotecnologia, Lavras, v. 28, n. 3, p. 614-620, maio/jun., 2004. Disponível em: <http://dx.doi.org/10.1590/S1413-70542004000300018>. Doi: 10.1590/S1413-70542004000300018

ESMAY, M. L. Principles of animal environment. $2^{\circ}$ ed. Westport: ABI Publishing, 1969. 325 p.

FURTADO, D. A.; AZEVEDO, P. V.; TINÔCO, I. F. F. Análise do conforto térmico em galpões avícolas com diferentes sistemas de acondicionamento. Revista Brasileira de Engenharia Agrícola e Ambiental, Campina Grande, v. 7, n. 3, p. 559-564, 2003. Disponível em: <http://dx.doi.org/10.1590/S1415-43662003000300025>. Doi: 10.1590/S1415-43662003000300025

FURTADO, D.; GOMES, C. A. V.; MEDEIROS, A. N.; FILHO, E. C. P.; JÚNIOR, V. L. Effects of thermal environment and supplementation levels on the physiological parameters of moxotó goats in confined and semi-confined rising systems. Engenharia Agrícola. [online]. vol.28, n.3, p.396-405, 2008. Disponível em: <http://dx.doi.org/10.1590/S0100-69162008000300001>. Doi: 10.1590/S010069162008000300001

RIBEIRO, N. L.; FURTADO, D. A.; MEDEIROS, A. N.; RIBEIRO, M. N.; SILVA, R. C. B.; SOUZA, C. M. S. Avaliação dos Índices de conforto térmico, parâmetros fisiológicos e gradiente térmico de ovinos nativos. Engenharia Agrícola, Jaboticabal, v. 28, n. 4, p. 614-623, out./dez. 2008. Disponível em: <http://dx.doi.org/10.1590/S0100-69162008000400001>. Doi: 10.1590/S010069162008000400001

LEITE, J. R. S.; FURTADO, D. A.; LEAL, A. F.; SOUZA, B. B.; SILVA, A. S.; Influência de fatores bioclimáticos nos índices produtivos e fisiológicos de caprinos nativos confinados. Revista Brasileira de Engenharia Agrícola e Ambiental, v. 16, n. 4, p. 443-448, 2012. <http://dx.doi.org/10.1590/S1415-43662012000400015>. Doi: $10.1590 / \mathrm{S} 1415-43662012000400015$

MCDOWELL, R. E. Bases biológicas de la producción animal en zonas tropicales. 1.ed. São Paulo: Ícone. 1989. 340p.

MEHDIZADEH, S.; BEHMANESH, J.; KHALILI, K. Application of gene expression programming to predict daily dew point temperatur. Applied Thermal Engineering, v.112, p.1097-1107, 2017. Disponível em: 
$<$ https://doi.org/10.1016/j.applthermaleng.2016.10.181>.

Doi: 10.1016/j.applthermaleng.2016.10.181

NACIONAL WEATHER SERVICE, s.d. Disponível em: <http://www.nws.noaa.gov/>. Acesso em: 13 mai. 2017.

PEREIRA, G. M.; SOUZA, B. B.; SILVA, A. M. A.; ROBERTO, J. V. B.; SILVA, C. M. B. A. Avaliação do comportamento fisiológico de caprinos da raça Saanen no semiárido paraibano. Revista Verde, Mossoró-RN, v. 6, n.1, p. 83-88 jan./mar. de $2011 . \quad$ Disponível em: <https://www.gvaa.com.br/revista/index.php/RVADS/article/view/525> .

SANTOS, F. C. B.; SOUZA, B. B.; ALFARO, C. E. P.; CEZAR, M. F.; FILHO, E. C. P.; ACOSTA, A. A. A.; SANTOS, J. R. S.; Adaptabilidade de caprinos exóticos e naturalizados ao clima semi-árido do nordeste brasileiro. Ciência e Agrotecnologia, Lavras, v. 29, n. 1, p. 142-149, jan./fev. 2005. Disponível em: <http://dx.doi.org/10.1590/S1413-70542005000100018> Doi: 10.1590/S141370542005000100018

SANTOS, F. S. M.; PIRES, J. E. P.; PEREIRA, A. M.; AZEVEDO, D. M. M. R.; ROCHA, R. R. C.; CARDOSO, F. S.; ARAUJO, A. M.; MURATORI, M. C. S.; COSTA, A. P. R. Adaptabilidade de caprinos Sannem e Marota mantidos em clima tropical semiúmido. Revista Brasileira de Saúde e produção Animal, Salvador, v. 15 , n. 4, p. 928-936 out./dez., 2014. http://dx.doi.org/10.1590/S151999402014000400020

SOUZA, A. P.; MOTA, L. L.; ZAMADEI, T.; MARTIM, C. C.; ALMEIDA, F. T. A.; PAULINO, J. Classificação climática e balanço hídrico climatológico no Estado de Mato Grosso. Nativa, Sinop, v. 01, n. 01, p.34-43, out./dez., 2013. Disponível em: <http://dx.doi.org/10.14583/2318-7670.v01n01a07>. Doi: $10.14583 / 2318$ 7670.v01n01a07

SOUZA, E. D.; SOUZA, B. B.; SOUZA, W. H.; CEZAR, M. F.; SANTOS, J. R. S.; TAVARES, G. P. Determinação dos parâmetros fisiológicos e gradiente térmico de diferentes grupos genéticos de caprinos no semi-árido. Ciência e Agrotecnologia, Lavras, v. $29, \quad$ n. 1, p. 177-184, jan./fev. 2005. Disponível em: <http://dx.doi.org/10.1590/S1413-70542005000100022>. Doi: 10.1590/S141370542005000100022 